\title{
Intersections of immigration law and family violence: Exploring barriers for ethnic migrant and refugee background women
}

Irene Ayallo, Unitec Institute of Technology, Aotearoa New Zealand

\begin{abstract}
INTRODUCTION: Action on family violence ${ }^{1}$ remains a policy priority for the New Zealand government. Accordingly, this article explores the Immigration New Zealand's Victims of Family Violence (VFV) visa. Specifically, it explores possible barriers preventing MELAA ${ }^{2}$ cultural groups from utilizing the VFV visa.

APPROACH: The discussion is based on administrative immigration data, gathered by Immigration New Zealand (INZ), on applicants for VFV visas between July 2010 and March 2021.
\end{abstract}

FINDINGS: Over the last 10 years, INZ received 1,947 applications for the VFV Visa. People of Asian (40\%) and Pacific (38\%) backgrounds made most of these applications, with India, Fiji, China, the Philippines, and Tonga making up the top five source countries. MELAA communities made only $11 \%$ of the total VFV visa applications. Applicants from South Africa, Brazil, Iran, Nigeria, and Argentina made up the top five source MELAA countries. Analyses showed that MELAA applications were mostly work-type visas.

IMPLICATIONS: Data presented shows that the VFV visa is still underutilised within these communities. Possible reasons for these notable outcomes are explored in this article, with suggestions for remediating strategies for barriers preventing MELAA communities from utilising the VFV visa. This article concludes that more research is required to gain an indepth understanding of the specific cultural contexts within which these women engage with this visa.

Keywords: Family violence and immigration policy; ethnic women and domestic violence; immigration and social work

\section{Family violence in Aotearoa New Zealand: The case of migrant and refugee-background women}

The high prevalence of domestic violence or, more inclusively, family violence in Aotearoa New Zealand, is now well established. Family violence, as defined in the Family Violence Act 2018, recognises various forms of abuse and coercion that are part of a pattern of behaviour and that causes cumulative harm. These include physical, sexual, and psychological abuse, coercion, or control. While there
AOTEAROA NEW ZEALAND SOCIAL WORK 33(4), 55-64.

CORRESPONDENCE TO: Irene Ayallo iayallo@unitec.ac.nz 
are men harmed in domestic violence situations, the overwhelming burden is borne by women (Fanslow \& Robinson, 2011). Women from across cultures, socioeconomic backgrounds, and relationship circumstances (both heterosexual and homosexual relationships) experience domestic violence regularly (Swarbrick, 2018). At least one in three women in Aotearoa New Zealand has experienced forms of sexual and / or physical violence in their lifetime (Fanslow \& Robinson, 2011). Statistics from many sources, collated by the New Zealand Family Violence Clearinghouse, show that the number of deaths caused by family violence has increased over the years. The majority of these are mostly perpetrated by men against women (New Zealand Family Violence Clearinghouse, 2017). The number of crisis calls received by women's refuges across the country has also increased over the years, as well as the number of women accessing community advocacy services and/or staying in safe houses (Shakti Community Council Inc., 2011). However, these statistics do not present the full picture of domestic violence in Aotearoa New Zealand. Domestic violence remains an underreported, and under-investigated, crime for various and complex reasons (Fanslow \& Robinson, 2004). There are extensive health and developmental consequences, with both short and long-term negative impacts, that stem from experiences of domestic violence (Fanslow \& Robinson, 2011). Consequently, there is an increasing demand for effective responses at micro and macro levels, through appropriate intervention programmes and legislation (Levine \& Benkert, 2011). While women from across backgrounds and statuses may have similar experiences of domestic violence, research shows that women of migrant and refugee backgrounds have unique and distinct experiences. This is mainly because the types and characteristics of family violence in these communities are particular to specific circumstances linked to the processes of immigration, resettlement, and integration in host communities. These include: immigration-law-related abuse; violence perpetrated and supported by multiple perpetrators which can be transnational; and there may be extant cultural values and practices that hinder help-seeking in situations of domestic violence (Simon-Kumar, 2019). These factors have been found to worsen migrant women's already vulnerable position in domestic violence situations (Kapur et al., 2017; Menjívar \& Salcido, 2002).

Globally, violence against women has been a subject of debate. Accordingly, most countries have drafted specific laws and national policies and/or ratified certain international conventions in seeking to prevent, eradicate, and punish violence against women. A study investigating domestic violence in many countries found that, of the 173 countries covered, 127 countries passed specific domestic violence laws. Countries that had not passed specific laws were found to still offer some form of increased protection for people experiencing domestic violence. However, the majority of these legislative protections were found to be incomplete or weak in implementation (Sifaki, 2017). In Aotearoa New Zealand, the Family Violence Act 2018, a revision of the Domestic Violence Act 1995, exists for this protective purpose. Family violence is contextually defined in this Act (Swarbrick, 2018). The effectiveness of these laws and policies should be measured by their ability to address important factors associated with family violence against women, and reduce personal and social consequences of domestic violence (Dugan, 2003; Sifaki, 2017).

Demographically, Aotearoa New Zealand is a multicultural society. The 2013 and 2018 population census identified at least 213 ethnic groups living in New Zealand. This is evidence that ethnic diversity is now an inevitable part of our society and should be considered in addressing family violence. Ethnic populations, as defined by the Ministry of Ethnic Communities and 
the New Zealand government (to include ethnicities from Asia, Africa, Continental Europe, Latin America, and the Middle East), represent almost $20 \%$ of the country's total population. The majority of people from these communities $(93 \%)$ were born overseas, and only $7 \%$ were born in Aotearoa New Zealand (Ministry for Ethnic Communities, 2020). Many reports and much research conclude that research on family violence among ethnic communities living in New Zealand, as a population group is limited (Rahmanipour et al., 2019). This dearth of research has also been noted in other countries (Menjívar \& Salcido, 2002). Accordingly, no official figures show the overall prevalence of family violence in these communities. However, a few studies have provided some useful estimates within specific ethnic communities (e.g., Simon-Kumar, 2019). Additionally, various community advocacy groups working with migrant and refugee-background women have highlighted the frequency and negative wellbeing impacts of domestic violence among these groups (Mayeda \& Vijaykumar, 2015; Simon-Kumar, 2019).

\section{Family violence in Aotearoa New Zealand: Immigration law-related risk factors}

In addition to the Family Violence Act (2018) and several international legal instruments ratified by Aotearoa New Zealand that relate to preventing violence against women, the country has a specific legislative and policy framework for recent migrants experiencing family violence (Ministry of Business, Innovation and Employment [MBIE], 2019). This is the Victims of Family Violence (VFV) policy visa, which uses the same definition of family violence as found in the Family Violence Act. The main purpose of the $\mathrm{VFV}$ visa is to provide people experiencing family violence, in most cases women, with visa status separate from their expartners'. Before 2002, women sponsored by their partners were not able to leave the relationship until after a two-year probation period (Burman \& Chantler, 2005). For instance, some women who decided to leave violent relationships after years of abuse subsequently became illegal under immigration law (Mayeda \& Vijaykumar, 2015)_women were not able to leave violent relationships because of their visa conditions (Harper, 2012). The policy particularly catered for women living with abusive partners, and not yet residents but plan to apply for residency based on that relationship. Their situation made them vulnerable to their partner's control and abuse, with threats to report them to Immigration New Zealand (INZ) or the Ministry of Social Development (MSD) (The New Zealand Psychological Society, 2015).

Migrants experiencing family violence can be granted temporary work visas and a resident visa under the VFV visa policy, upon meeting certain requirements. These include providing evidence and proof that the person applying for this visa was in a relationship with an Aotearoa New Zealand citizen or resident; that they had planned to apply for a residence visa based on this relationship; the relationship has now ended because of family violence; and that the applicant now need to work to support themselves. Further evidence that the applicant is unable to return to their country of origin, because of financial incapability or social stigma, is required if they choose to apply for a residence class visa. A temporary work visa can be granted and is valid for six months, with the possibility of this being extended to nine months if the applicant applies for a residence visa (New Zealand Immigration, 2018; MBIE, 2019). In a later section, the author will return to discuss the link between the low application numbers for VFV visas to the challenges in meeting these requirements and providing evidence acceptable to INZ.

The VFV visa policy is timely and aligns with findings from literature and research, which have established 
that immigration legal status increases women's vulnerability to family violence (Harzig, 2003; Kapur et al., 2017). Research emerging from countries with comparable legislative and policy frameworks for family violence to Aotearoa New Zealand, including Australia, Canada, and the USA, shows that visa status is a major risk factor in family violence situations. Because of the gendered nature of immigration, women are mostly the victims because their legal status in the country is often tied to their partner's visa (Erez et al., 2009). In New Zealand, it has been observed that women in a probation visa period and / or on temporary visas are the most at risk of family violence (SimonKumar, 2019). Generally, the risk of family violence increases if the woman relies on their abusive partner for sponsorship. The immigration policy was amended to protect women caught in such situations.

\section{A review of VFV visa administrative data between July 2010 and March 2021}

INZ gathers administration data on VFV visa applications. This data is available to the public through the Ministry of Business, Innovation \& Employment (MBIE) website. The "Visa Flows" sub-section of the migration datasets provides data on how migrants move in and out of Visa Categories in New Zealand (MBIE, 2021).

\section{Method of generating data from datasets}

The following steps were taken to explore the data set for this article. The data sets of interest were selected (Flows: “W1 Work Decisions" and "R1 Residence Decisions," respectively); the period was set to "Calendar Year"; two variables of interest were selected, including "Application Criteria" and "Decision Type"; and finally, additional filters added, including "Nationality" and "Application Criteria - Victims of Domestic Violence." These steps generated data showing numbers of applicants for VFV visas between July 2010 and March 2021, by nationality and the decision outcomes (Approved or Declined) for the number of visa applications. The full data were downloaded as comma-separated values (CSV) files for further analysis. These are reported below. For further analysis the data were grouped according to "regions," closely following Statistics New Zealand's official "Ethnic" (termed Region in this article) categories.

Table 1 shows the decision outcomes for the number of VFV visa applications over the last 10 years (July 2010 to March 2021) (MBIE, 2021).

Table 1. Decision Outcomes for VFV Visa Applications 2010-2021

\begin{tabular}{|c|c|c|c|}
\hline \multirow{2}{*}{ Region } & \multicolumn{2}{|c|}{ Type of Application } & \multirow{2}{*}{ Total Applications } \\
\hline & Work Visa & Residence visa & \\
\hline $\begin{array}{l}\text { Asia (ALL) } \\
786 \text { Applications }\end{array}$ & $\begin{array}{l}540 \text { Applications } \\
\text { (A: 480; D: } 60)\end{array}$ & $\begin{array}{l}246 \text { Applications } \\
\text { (A: 189; D: 57) }\end{array}$ & $\begin{array}{l}669 \text { Approved } \\
117 \text { Declined }\end{array}$ \\
\hline $\begin{array}{l}\text { Pacific (ALL) } \\
732 \text { Applications }\end{array}$ & $\begin{array}{l}462 \text { Applications } \\
\text { (A: 408; D: 54) }\end{array}$ & $\begin{array}{l}270 \text { Applications } \\
\text { (A: 198; D: 72) }\end{array}$ & $\begin{array}{l}606 \text { Approved } \\
126 \text { Declined }\end{array}$ \\
\hline $\begin{array}{l}\text { MELAA (ALL) } \\
222 \text { Applications }\end{array}$ & $\begin{array}{l}141 \text { Applications } \\
\text { (A: 126; D: 15) }\end{array}$ & $\begin{array}{l}81 \text { Applications } \\
\text { (A: 54; D: 27) }\end{array}$ & $\begin{array}{l}180 \text { Approved } \\
42 \text { Declined }\end{array}$ \\
\hline $\begin{array}{l}\text { Europe (ALL) } \\
207 \text { Applications }\end{array}$ & $\begin{array}{l}138 \text { Applications } \\
\text { (A: 129; D: 9) }\end{array}$ & $\begin{array}{l}69 \text { Applications } \\
\text { (A: 30; D: 39) }\end{array}$ & $\begin{array}{l}159 \text { Approved } \\
48 \text { Declined }\end{array}$ \\
\hline Total $=1947$ & 1281 Applications & 666 Applications & A: $1614 ; D: 333$ \\
\hline
\end{tabular}


The largest group of applicants were from Asia (40\%), and the Pacific (38\%) regions. Applicants from MELAA and Europe regions made up only $11 \%$ of the applications, respectively. Most of the applications were for temporary work visas $(66 \%)$, and the remaining were residence visas (34\%). With an additional requirement of proof of inability to return to the country of origin because of financial incapacity and social stigma, it could be argued that temporary work visas would logically make up the majority of the VFV visas applications. Generally, the approval rates were high for both visa types with 83\% approved decision outcomes and only $17 \%$ declined decision outcomes.

Figure 1 shows the VFV work visa application over the last 10 years by nationality. India and Fiji are among the top source countries for a VFV work visa with China, the Philippines, and Tonga. The pattern is also reflected for the VFV residence visas. Generally, research supports the fact that applicant countries for INZ's VFV visa reflect those countries with high prevalence of family violence-India, China, the Philippines, Fiji, and Tonga remain within Aotearoa New Zealand's top source countries of applicants for the last 10 years.

A total of 222 applications (11\%) were made by people from the MELAA regions, with $64 \%$ of these being work visa applications and $36 \%$ residence visa applications. Table 2 shows the decision outcomes for the number of VFV visa applications from the MELAA region over the last 10 years (Jul 2010 to March 2021) (MBIE, 2021).

Applicants from Africa (43\%) and Latin America $(38 \%)$ made up the majority of VFV visa applications from the MELAA region. Only $19 \%$ of the applications were made by people from the Middle East. The following VFV visa applications by nationality further shows that South Africa and Brazil are among the top source countries for a VFV work visa with Iran, Nigeria, and Argentina. As shown in Figure 2, the pattern is also reflected for the VFV residence visa applications from this region.

Figure 1 VFV Work Visa Applications by Nationality-Top Five Countries.

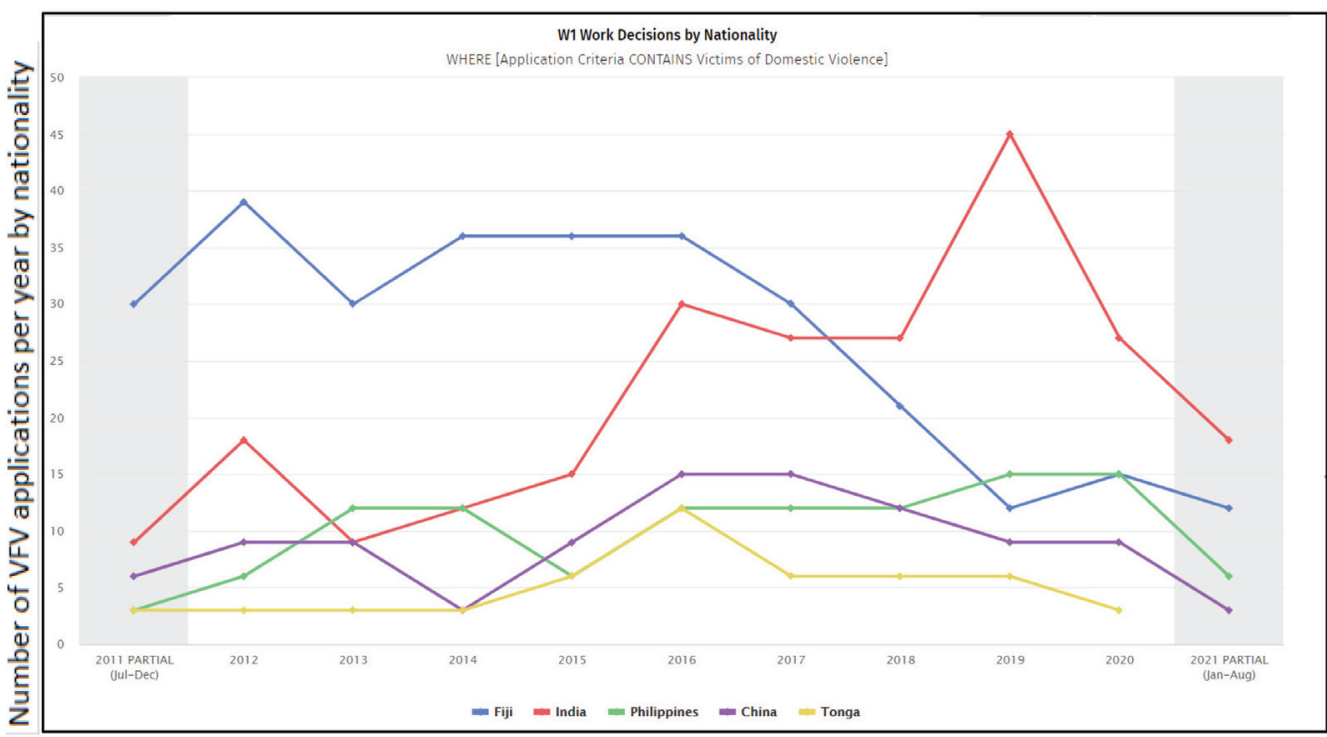

VFV Applications per year by nationality

Note: Reproduced from INZ administrative data sourced from https://mbienz.shinyapps.io/migration_data_ explorer/\# accessed 6 June 2021. 
Table 2. Decision Outcomes for VFV Visa Applications-MELAA Regions

\begin{tabular}{|c|c|c|c|}
\hline \multirow{2}{*}{$\begin{array}{l}\text { Region } \\
\mathrm{N}=222\end{array}$} & \multicolumn{2}{|c|}{ Type of Application } & \multirow[b]{2}{*}{ Total Applications } \\
\hline & Work Visa & Residence visa & \\
\hline $\begin{array}{l}\text { Africa } \\
96(43 \%)\end{array}$ & $\begin{array}{l}51 \\
(A: 45 D: 6)\end{array}$ & $\begin{array}{l}45 \\
(A: 30 \mathrm{D}: 15)\end{array}$ & $\begin{array}{l}75 \text { Approved } \\
21 \text { Declined }\end{array}$ \\
\hline $\begin{array}{l}\text { Latin America } \\
84(38 \%)\end{array}$ & $\begin{array}{l}57 \\
(A: 51 \mathrm{D}: 6)\end{array}$ & $\begin{array}{l}27 \\
(A: 15 D: 12)\end{array}$ & $\begin{array}{l}66 \text { Approved } \\
18 \text { Declined }\end{array}$ \\
\hline $\begin{array}{l}\text { Middle East } \\
42(19 \%)\end{array}$ & $\begin{array}{l}33 \\
(A: 30 \mathrm{D}: 3)\end{array}$ & $\begin{array}{l}9 \\
(A: 9 \mathrm{D}: 0)\end{array}$ & $\begin{array}{l}39 \text { Approved } \\
3 \text { Declined }\end{array}$ \\
\hline
\end{tabular}

As shown in Table 3, the number of applications for the VFV visa from MELAA region countries is low compared to those of the overall top five countries (India, China, the Philippines, Fiji, and Tonga) (MBIE, 2021).

These administrative data reported so far show that, generally, the applications rates for the VFV visas are far lower than incidence of abuse (Simon-Kumar, 2019), with only a total of 1947 applications made between July 2010 and March 2021.
This number is even lower for MELAA communities, with only $222(11 \%)$ of the total applications made by people from this region.

This rate of application by people from MELAA communities is disproportionate to the population share of MELAA people living in Aotearoa New Zealand. According to the Ministry of Ethnic Communities (2021), nearly 3\% (120,000 people) of the New Zealand population are from these communities. A comparison of the

Figure 2 VFV Work Visa Applications by Nationality-Top Five MELAA Countries.

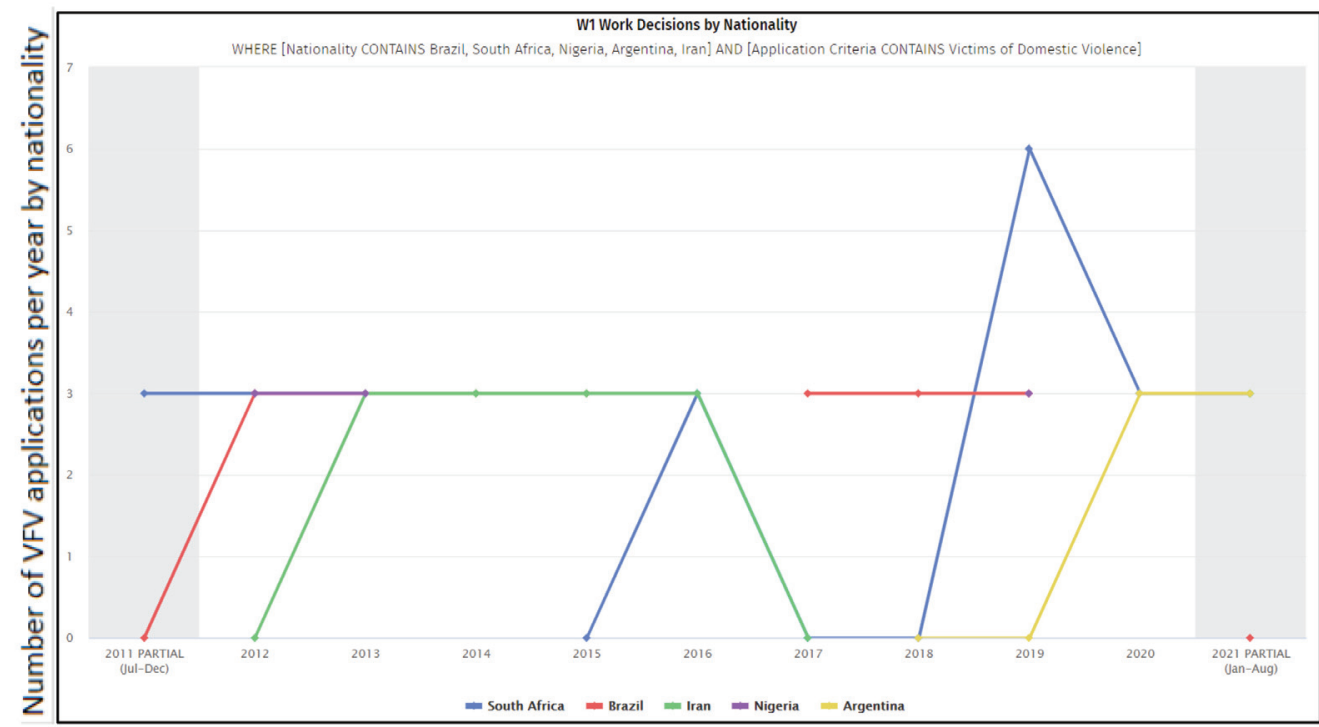

VFV Applications per year by nationality

Note: Reproduced from INZ administrative data sourced from https://mbienz.shinyapps.io/migration_data_ explorer/\# accessed 6 June 2021. 
Table 3. Decision Outcomes for VFV Visa Applications by Nationality-Top Five Overall Source Countries Compared with Top Five Source MELAA Countries

\begin{tabular}{|c|c|c|c|c|c|}
\hline \multirow{2}{*}{$\begin{array}{l}\text { Top } 5 \text { VFV visa } \\
\text { source countries }\end{array}$} & \multicolumn{2}{|c|}{ Type of Application } & \multirow{2}{*}{$\begin{array}{c}\text { To } 5 \text { VFV visa source } \\
\text { MELAA countries }\end{array}$} & \multicolumn{2}{|c|}{ Type of Application } \\
\hline & Work Visa & $\begin{array}{l}\text { Residence } \\
\text { visa }\end{array}$ & & Work Visa & $\begin{array}{c}\text { Residence } \\
\text { visa }\end{array}$ \\
\hline Fiji (540) & 354 & 186 & South Africa (48) & 21 & 27 \\
\hline India (345) & 246 & 99 & Brazil (42) & 30 & 12 \\
\hline Philippines (150) & 108 & 42 & Iran (15) & 12 & 3 \\
\hline China (135) & 87 & 48 & Nigeria (12) & 6 & 6 \\
\hline Tonga (111) & 63 & 48 & Argentina (12) & 9 & 3 \\
\hline
\end{tabular}

VFV visa application rates (a total of 222 applications) and the population share of this group $(120,000)$ may, logically, suggest that there is an over-representation in the VFV applicants from MELAA populations. Conversely, reports by various communitybased agencies and organizations show that family violence is frequent and with negative (often severe) impacts in these communities (MBIE, 2019; Simon-Kumar, 2019). International studies show that ethnic communities, including MELAA people, have a comparatively lower inclination to report family violence (Mayeda \& Vijaykumar, 2015). Nair (2017), discussing help-seeking patterns in situations of family violence, observes that ethnic women often only seek help when there are severe physical and mental health impacts. Even then, many remain reluctant to formally disclose/ report family violence experiences. Accordingly, the under-utilisation of the VFV visa is by no means a reflection of the lack of family violence experienced in these communities.

In theory, the application trends reported support research that shows that applicant countries for the VFV visa reflect those countries that have high occurrences of family violence (MBIE, 2019). In the case of ethnic communities, this is often further linked to the prevalence of violence in their countries of origin (Nair, 2017). This is somewhat verifiable. Data from across numerous international surveys on violence against women, for instance, shows a relatively high lifetime prevalence of domestic violence in the top five VFV visa source MELAA countries (South Africa, Brazil, Iran, Nigeria, and Argentina) (Kendall, 2020; World Health Organisation, 2021). While there are no bilateral, comparative studies (between each of these countries and Aotearoa New Zealand) extant international and national studies have found that the nature and characteristics of family violence change significantly because of the act and process of immigration (Simon-Kumar, 2019).

Somasekhar (2016) even argued that factors unique to immigration make ethnic women even more vulnerable to family violence in host countries as compared to women in their countries of origin. The process of immigration can become an instigator for family violence (MBIE, 2019). For instance, people bring their culture with them during the process of immigration. At the same time, they leave behind some practices and resources that may support them during adversity. Some of these 
changes have implications for help-seeking behaviours, along with reporting (Nair, 2017). Accordingly, the under-utilisation of the VFV visa postulated in the data reported may reflect immigration-related factors such as fear of isolation and shame from and towards their communities that may be linked to reporting family violence (Simon-Kumar, 2018). Overall, the data trends indicate possible barriers to seeking and obtaining the Victims of Family Violence visa.

\section{Discussion: Some barriers and remediating strategies}

Overall, $66 \%$ of the VFV visa applications were for the temporary work type visa. This suggests that finance is a factor in these abusive relationships and a reason for people leaving and seeking their visa status separate from their ex-partners. Proof that the person now needs to work to support themselves is one of the main requirements for this type of visa application. It is now established that financial incapability is a risk factor in situations of violent relationships, and especially if the person is dependent on the abuser for financial support. The threat to withdraw financial support is often a weapon used by the abuser. Lack of employment or underemployment is associated with men's perpetration of domestic violence (Nair, 2017). While this is not specific to migrant women, migrationspecific factors such as visa restrictions which do not allow work rights and benefits assistance increase these women's vulnerability in such situations (Levine \& Benkert, 2011).

According to the perceptions of some non-governmental organisations (NGOs) which have assisted women with VFV visa applications, the process is timeconsuming and complex and, because of this, often has financial implications for the applicant (MBIE, 2019). For instance, one of the acceptable forms of evidence that the relationship has now ended because of family violence is the final Protection Order against the perpetrator. This is in theory costfree. In practice, however, many applicants will require the assistance of a lawyer to apply. Yet legal aid may only be available for people eligible for a benefit or on a low income. Otherwise, the cost is met by the applicant (MBIE, 2019). This then becomes a barrier for women without any rights to work and / or receive benefit assistance (Dew, 2017). In addition, other acceptable forms of evidence such as police and medical checks also cost money.

Women who successfully apply for a VFV work visa are granted an Interim Visa during processing. However, this does not grant their holders work rights. This is especially problematic because applicants are not eligible for benefits assistance during this time when their visa application is being processed. An automatic process of varying visa conditions to allow work rights, for Interim Visa holders, has been proposed by some NGOs to remedy this barrier (MBIE, 2019).

The relatively low number of residencetype visa applications, only $34 \%$ of the total VFV visa applications, suggests additional barriers exist to obtaining the VFV visa. The temporary work visa is only valid for 6 months. This can be extended, to 9 months, if the applicant applies for the residence type visa. The additional requirement for this visa type is evidence of inability to return to the country of origin owing to financial incapability or social stigma. The low numbers of applications reflect, among other factors, the difficulties in meeting VFV visa requirements. One of the most problematic aspects, highlighted by some NGOs working with women in such situations, is the main requirement that the relationship is, or was, with a partner who is a resident or citizen of Aotearoa New Zealand. Yet existing research now shows that the majority of such violence is perpetrated by partners holding temporary visas. Women in such situations are ineligible for VFV visas, even when they would face significant hardship in their home country (Burman 
\& Chantler, 2005; Simon-Kumar, 2018).

The perpetrator can also take advantage of the situation this requirement creates, whereby their immigration status determines the immigration options available for the woman. For instance, the perpetrator, even though eligible to apply for residence in Aotearoa New Zealand, prefers to remain on a temporary visa to keep the woman dependent on them. Perpetrators on longterm temporary visas with high-paid employment and already eligible for other publicly funded services may see no need for the other benefits that residence offers and / or simply use this as a power tool. Rightly, the determining factor for the immigration status of a woman in such a situation should not be a partnership with an Aotearoa New Zealand citizen or resident but their inability to return to their home country. Additionally, as suggested by some NGOs, at the very least women whose abusers were on long-term temporary visas should be automatically eligible for VFV visas (MBIE, 2019).

\section{Conclusion}

The experiences of family violence among migrant and refugee-background women are unique and distinct. This is mainly because the types and characteristics of family violence in these communities are linked to specific circumstances created by the processes of immigration, resettlement, and integration in host communities. Immigration law-related abuse is explored, highlighting that existing legislation and policy may create situations that increase women's vulnerability in abusive relationships by inadvertently making them dependent on the abuser. Women experiencing violence, and who are dependent on the immigration status of their abusive partner, may find it difficult to leave abusive relationships for several reasons, including fear of losing financial support and legal status in the country. The VFV visa is a good initiative by Immigration New Zealand, as a macro-level approach of removing the perpetrator's power to manipulate the women using their immigration status.

INZ administrative data on VFV visa applications made between July 2010 and March 2021 shows a low number of applications overall, and specifically from MELAA communities. This is an indication that, within these communities, the VFV visa type is still underutilised. Barriers explored in this article include the difficulties in meeting some of the main requirements and / or providing proof to successfully lodge an application and obtain a VFV visa. The complexity of the application process and associated financial implications form a major barrier. Additionally, by and large, the VFV visa policy still creates situations where the perpetrators' immigration status determines the immigration options available for the person experiencing family violence. Practical and accessible ways of "variation of conditions" to allow women work rights when experiencing violence and/or applying for this visa even if the perpetrator is on a temporary visa are recommended.

A more thorough conceptualisation of migrant women's perceptions on the VFV visa policy, specifically views of women who have successfully or unsuccessfully obtained these visas, could help identify and remediate further barriers to the utilisation of this visa. Further research is required with these women to establish how these barriers might be impacting VFV applications within their specific cultural contexts.

\section{Notes}

1 The terms family violence and domestic violence are used interchangeably in this article.

2 MEELA is an official standard classification used by Statistics New Zealand to group people of Middle Eastern/Latin America/African ethnic groups. http://archive.stats.govt.nz/methods/research-papers/ topss/comp-ethnic-admin-data-census/classification-ofethnicity.aspx\#gsc.tab=0

Accepted 30 Novermber 2021

Published 23 December 2021 


\section{References}

Burman, E., \& Chantler, K. (2005). Domestic violence and minoritisation: Legal and policy barriers facing minoritized women leaving violent relationships. International Journal of Law and Psychiatry, 28(1), 59-74.

Dew, J. (2017). Special visas for victims of domestic violence - The challenges. https://blog.laurentlaw.co.nz/ 2017/09/27/special-visas-for-victims-of-domesticviolence-the-challenges/

Dugan, L. (2003). Domestic violence legislation: Exploring its impact on the likelihood of domestic violence, police involvement, and arrest. Criminology \& Public Policy, 2(2), 283-312.

Erez, E., Adelman, M., \& Gregory, C. (2009). Intersections of immigration and domestic violence: Voices of battered immigrant women. Feminist Criminology, 4(1), 32-56.

Fanslow, J., \& Robinson, E. (2004). Violence against women in New Zealand: Prevalence and health consequences. The New Zealand Medical Journal (Online), 117(1206).

Fanslow, J. L., \& Robinson, E. M. (2011). Sticks, stones, or words? Counting the prevalence of different types of intimate partner violence reported by New Zealand women. Journal of Aggression, Maltreatment \& Trauma, 20(7), 741-759.

Harper, L. (2012). Visas tie them to violent partners. http://www.stuff.co.nz/taranaki-daily-news/ news/7257211/Visas-tie-them-to-violent-partners

Harzig, C. (2003). Immigration policies: A gendered historica comparison. In M. Morokvasic, U. Erel, \& K. Shinozaki (Eds.), Crossing borders and shifting boundaries (pp. 35-58). Springer.

Kapur, S., Zajicek, A., \& Hunt, V. (2017). Immigration provisions in the Violence Against Women Act: Implications for Asian Indian marriage migrants. Journal of Women, Politics, \& Policy, 38(4), 456-480.

Kendall T. (2020). A synthesis of evidence on the collection and use of administrative data on violence against women. UN Women. https://www. unwomen.org/-/ media/headquarters/attachments/sections/library/ publications/2020/synthesis-of-evidence-on-collectionand-use-of-administrative-data-on-vaw-en.pdf

Levine, M., \& Benkert, N. (2011). Case studies of community initiatives addressing family violence in refugee and migrant communities: Final report. Ministry of Social Development and Ministry of Women's Affairs.

Mayeda, D. T., \& Vijaykumar, R. (2015). Intersections of culture, migration, and intimate partner violence as told by migrant youth. International Journal of Criminology and Sociology, 4, 208-219.

Ministry of Business Innovation and Employment. (2019). Recent migrant victims of family violence project 2019: Final report. https://www.mbie.govt.nz/ dmsdocument/12138-recent-migrant-victims-of-familyviolence-project-2019-final-report

Ministry of Business Innovation and Employment (2021) Migration data explorer. https://www.tia.org.nz/ resources-and-tools/insight/migration-data-explorer/

Ministry for Ethnic Communities. (2020). Ethnic communities data dashboard. https://app.powerbi.com/ew?r=eyJrljoiZ DQ3ZWJkNGMtYTcxMi00Yzc1LWI2Mzkt ZGFiMTBkNmVjMmFmliwidCI6ImY2NTIjYTV jLWZjNDctNGU5Ni1iMjRkLTE0Yzk1ZGYxM2FjYiJ9.
Menjívar, C., \& Salcido, O. (2002). Immigrant women and domestic violence: Common experiences in different countries. Gender \& Society, 16(6), 898-920.

Nair, S. (2017). Elephant in the therapy room: Counselling experiences of ethnic immigrant women survivors of family violence in Aotearoa, New Zealand [Master's thesis]. University of Auckland. https://nzfvc.org.nz/sites/ nzfvc.org.nz/files/Shila-Nair-MCOUN-Research-PaperDec-2017.pdf

New Zealand Family Violence Clearinghouse. (2017). NZFVC Data Summaries 2017: Family violence reports reach record high. https://nzfvc.org.nz/news/nzfvc-datasummaries-2017-family-violence-reports-reach-record-high

New Zealand Immigration. (2018). New Zealand Immigration operational manual. https://www.immigration.govt.nz/ opsmanual/\#35439.htm

New Zealand Psychological Society. (2015). Submission on behalf of the New Zealand Psychological Society on the Review of Family Violence Law. http://www.psychology. org.nz/wp-content/uploads/Family-Violence-Law-ReviewSubmission.pdf

Rahmanipour, S., Kumar, S., \& Simon-Kumar, R. (2019). Underreporting sexual violence among "ethnic" migrant women: Perspectives from Aotearoa/New Zealand. Culture, Health \& Sexuality, 21(7), 837-852.

Shakti Community Council Inc. (2011). Status of immigrant women. https://tbinternet.ohchr.org/Treaties/CEDAW/ Shared\%20Documents/NZL/INT_CEDAW_NGO NZL_52_9821_E.pdf

Sifaki, E. (2017). What political dynamics lead to domestic violence legislation being implemented? https://newint. org/blog/2017/03/08/what-political-dynamics-lead-todomestic-violence-legislation

Simon-Kumar, R. (2018). Inclusionary policy and marginalised groups in Aoteaora/New Zealand process, impacts and politics. Kōtuitui: New Zealand Journal of Social Sciences Online, 13(2), 246-260.

Simon-Kumar, R. (2019). Ethnic perspectives on family violence in Aotearoa New Zealand. Auckland, New Zealand. New Zealand Family Violence Clearinghouse, University of Auckland.

Somasekhar, S. (2016). "What will people think?" Indian women and domestic violence in Aotearoa/New Zealand. University of Waikato.

Swarbrick, N. (2018). Domestic violence. http://www.TeAra. govt.nz/endomestic-violence/print

World Health Organization. (2021). Violence against women fact sheet. https://www.who.int/news-room/fact-sheets/ detail/violence-against-women 